\title{
Stability and Fluidity in Friendship Patterns of Kindergarteners: Does Children's Emotion Regulation and Maternal Friendship Management Matters?
}

\author{
Mi Hyun Park, Kyung Ja Park \\ Department of Child \& Family Studies, Yonsei University, Seoul, Korea \\ 유아의 단기 종단적 친구관계 변화 유형에 대한 유아의 정서 조절과 \\ 어머니 친구관계 관여의 영향 \\ 박미현, 박경자 \\ 연세대학교 아동·가족학과
}

\begin{abstract}
Objective: This two-wave study examined changes in kindergarteners' friendship patterns and their associations with emotion regulation and parental involvement in friendship management. Methods: Participants were 275 5-year-old children (138 girls and 137 boys) attending kindergartens in Korea. Utilizing nomination methods, each child identified three children as his/ her friends twice in 5 months. Teachers rated the children's emotion regulation and mothers rated their involvement with children. The data were analyzed by descriptive statistics, t-tests, and logistic regressions.

Results: Children were classified into five groups according to their friendship stability in 5 months; stable, fluid, gain, loss, friendless. Kindergarteners with higher emotion regulation were more likely to belong to stable, fluid, gain and loss friendship groups than the friendless kindergarteners. Children whose mothers reported higher mediation and supervision in children's friendship establishment were more likely to belong to the friendship gain group than the friendless group. Children whose mothers expressed higher levels of concerns and advice to children were more likely to be in the fluid group than the gain one.

Conclusion: Children's dispositions to control emotions and the mothers' involvement in children's making friends facilitate children's maintenance or making friendships.
\end{abstract}

Keywords: friendship patterns, emotion regulation, parental involvement in children's friendship

\section{서론}

인간의 삶에서 건강과 행복감을 유지하는 데 자주 언급되는 요인 중 하나는 좋은 친구를 갖는 것이다. 친구관계는 두 개인 이 서로를 좋아하고 친밀하게 여기며 정서적 유대감을 느끼는

Corresponding Author: Mihyun Park, Department of Child \& Family Studies, Yonsei University, 50 Yonsei-ro, Sedaemun-gu, Seoul, Korea, 03722

E-mail: kssopi@empal.com
관계로 보통의 또래와는 다르게 지각하는 관계이다(Berndt \& McCandless, 2009; Cillessen, 2009). 유아기에 친구가 생기기 시 작하면서 친구관계는 중요한 의미를 가질 수 있다.

유아는 친구와 상호 호혜적인 놀이를 하면서 의사소통 능 력, 문제 해결 능력, 갈등 관리, 조망 수용을 발달시키게 된

(C)The Korean Association of Child Studies

This is an Open Access article distributed under the terms of the Creative Commons Attribution Non-Commercial License (http:// creativecommons.org/licenses/by-nc/4.0) which permits unrestricted noncommercial use, distribution, and reproduction in any medium, provided the original work is properly cited. 
다(Bukowski, Buhrmester, \& Underwood, 2011; Howes, 2009; Rose-Krasnor \& Denham, 2009). 또한 부모나 형제와의 관계가 사회 규범과 기술을 전수하고자하는 수직적인 특성을 갖는 것 에 비해 유아기의 친구관계는 능력과 기술이 비슷한 수준의 유아들 간에 좀 더 수평적인 특징을 가지게 된다. 이러한 친구 와의 상호작용을 통해 유아들은 친밀감을 느낄 수 있고 협상 과 공동 구성을 경험하면서 상호 호혜적인 주고받기를 배울 수 있게 된다(Howes, 2009). 이러한 기술은 유아가 커 가면서 다른 사람들과 친밀한 사회적 관계를 형성하고 유지하는데 기 초가 된다(Kostelnik, Whiren, Soderman, \& Gregory, 2009).

학령기 후기의 친구관계는 신뢰감과 헌신, 충성심, 정서적 유대감이 주된 특징인 반면 유아기의 친구관계는 공유 활동과 근접성이 중요하다는 측면에서(Howes, 2009) Sullivan이 의미 하는 친구관계와는 질적으로 차이가 있지만, 유아도 친밀한 친 구관계를 형성할 수 있고, 이 시기에 친구관계를 형성하는 것 은 중요한 사회화 과정이다. Howes (1990)은 어린 유아들도 특 별히 선호하는 놀이 상대가 있어서 다른 보통의 또래들과 다른 상호작용을 보이며 친구관계를 형성할 수 있고 이들의 친구관 계는 안정적으로 유지되는 경향이 있음을 보고하였다.

유아기에 친구가 있는 것도 중요하지만 친구관계를 오랫 동안 유지하는 것은 친구 간에 친밀감과 정서적 유대감을 발 달시킬 수 있으므로 의미 있는 일이다. 유아가 친구관계를 유 지하려면 상호간에 관심을 공유하고 자기 노출을 하면서 관 계를 지속하려는 의도적인 노력을 해야 한다. 친구와의 관 계를 지속시키기 위해 노력을 기울이는 과정에서 유아는 타 인의 욕구와 감정에 대해 관심을 기울이고 정확하게 인식하 는 능력이 발달하게 된다. 뿐만 아니라 친구와 친구관계를 유 지하는 것은 서로에게 정서적 지지를 해줌으로써 사회적 환 경에 적응하고 심리적 안녕감을 유지하는데 결정적인 역할 을 할 수 있다(Ladd, Kochenderfer, \& Coleman, 1996; Proulx \& Poulin, 2013).

유아기 친구관계가 안정적으로 유지되는지를 살펴본 연구 자들은 시간의 흐름에 따라 동일한 친구와 친구관계를 계속 유지하는지를 의미하는 '친구관계의 안정성'을 중심으로 연구 하였다(Ladd et al., 1996; Sebanc, Kearns, Hernandez, \& Galvin, 2007). 유아기에는 친구관계에 변화가 많은 시기이므로 동일 한 유아와 친구관계를 유지하는 친구관계의 안정성과 함께 친 구관계의 변화유형을 살펴보아야 한다. 6 개월 동안 유아는 동 일한 친구와 관계를 유지하기도 했지만 새로운 친구를 형성하 거나 친구를 잃게 되거나 친구를 계속 사귀지 못하기도 하였 다(M. H. Park \& Park, 2016; Proulx \& Poulin, 2013). 그러나 이
연구들은 어떤 요인에 의해서 친구관계가 안정성을 보이거나 변화할 수 있는지에 대해서는 밝히지 못하였다. 따라서 유아 의 종단적 친구관계의 변화유형을 살펴보고, 이러한 친구관계 의 변화유형은 어떤 요인에 의해서 개인차가 나타날 수 있는 지를 알아볼 필요가 있다.

친구관계의 변화 유형에 영향을 미치는 개인내적인 요인 으로 정서 조절을 들 수 있다. 정서 조절은 필요한 상황에서 정서의 경험과 표현의 강도, 빈도 등을 너무 과하지도 너무 낮지도 않게 자신이나 사회적 파트너의 목표와 기대에 충족 시키도록 조절하는 것이다(Denham et al., 2003). 연구자들은 학령 전 아동이 좌절감과 분노와 같은 부정적 정서를 어떻게 조절하고 표현할 수 있는지와 같은 정서적 능력이 사회적 상 호작용에서 타인들과 긍정적인 관계를 계속 유지하면서 개 인적 목표를 성취하는 사회적 유능성에 결정적인 영향을 미 친다고 제시하였다(Eisenberg, Fabes, Murphy, Maszk, Smith, \& Karbon, 2008; Rubin, Bukowski, \& Parker, 2006). 특히 유아기 아동이 친구를 사귀고 친구관계를 유지하기 위해서는 정서 를 조절하는 능력이 필요하다(Hay, Payne, \& Chadwick, 2004; Rubin, Wojslawowicz, Rose-Krasnor, Booth-LaForce, \& Burgess, 2006).

선행연구를 살펴보면, 또래와의 상호작용에서 많이 웃고 행복감을 표현하며 부정적 정서를 사회적 상황에 적절하게 맞 추어 조정할 수 있는 유아는 또래와 함께 하는 놀이에 더 많이 참여했고, 협력적인 놀이를 계속 이어가고, 친사회적인 행동 을 하였다. 이러한 유아는 성인으로부터 사회적으로 유능하 다고 평가 받았을 뿐 아니라 또래에게도 같이 놀고 싶어 하는 유아로 선호되었으며 친구가 있을 가능성이 높았다(Denham et al., 2003; Keane \& Calkins, 2004). 반면 놀이 중에 자신의 의 견만 주장하고 화와 두려움 같은 부정적인 정서를 잘 조절하 지 못하는 유아는 또래에게 공격적으로 행동하거나 위축된 행 동을 보였고 또래와의 놀이에 참여하지 않으려고 했다. 이러 한 유아는 교사로부터 사회적으로 유능하지 못하다고 평가 받 았고 또래에게 거부당할 가능성이 높았으며 시간이 흐른 뒤 에는 친구가 없고 혼자 놀이하는 경향이 있었다(Denham et al., 2003; Eivers, Brendgen, Vitaro, \& Borge, 2012; Spinrad, et al., 2004). 따라서 또래와의 상호작용 중에 자신의 부적인 정서를 상대방이 불편하지 않게 표현하고 타인의 기분을 적절하게 인 식하여 반응하는 정서 조절은 친구관계를 형성하고 유지하는 양상을 이해하는데 도움이 된다.

친구관계의 변화 유형에 영향을 미칠 수 있는 환경적인 요 인으로 어머니의 역할을 들 수 있다. 가족은 유아가 최초로 접 
하는 사회적 맥락으로서 유아의 친구관계 발달에 영향을 미칠 수 있는 중요한 체계이다. 부모는 유아의 사회화 과정에서 가 족 체계와 사회적 관계를 이어주는 다리 역할을 한다(Parke, et al., 2002). 특히 어머니는 유아가 최초로 사회적 관계를 맺는 주 양육자로서 영·유아기와 대부분의 시간을 함께 보내며 상 호작용하기 때문에 연구자들의 주목을 받아 왔다.

이제까지 행해진 대부분의 선행연구는 어머니가 유아의 사회화 과정에 영향을 미치는 간접적인 방법을 살펴보았다. 예를 들어, 어머니의 전반적인 양육행동이나 애착 유형이 유 아의 친구관계에 어떤 영향을 미치는지 살펴보았다(Ladd \& Pettit, 2002; Parke, et al., 2002). 이러한 연구는 유아의 친구관 계에 미치는 간접적인 경로를 유추할 수 있으나 어머니의 어 떤 행동이 유아의 친구관계에 도움을 줄 수 있는지 구체적인 정보는 주지 못한다. 따라서 어머니의 어떤 노력이 직접적으 로 유아의 친구관계에 영향을 미치는지 살펴볼 필요가 있다.

어머니가 자녀의 친구관계에 영향을 주는 직접적인 역할 로 친구관계 관여를 들 수 있다. 친구관계 관여는 어머니가 유 아의 친구관계 기술을 향상시키고 친구관계를 촉진하기 위 해 의도적으로 행하는 노력을 의미한다(Bonnet, Gooseens, \& Schuengel, 2011; Ladd \& Pettit, 2002). 학령기 아동에 비해 유 아기 아동은 자유롭게 혼자 이동하는데 제한이 있어 어디에서 어떤 유아를 만나게 될지 또래 관계의 기회 자체를 어머니가 선택하여 제공해주는 측면이 강하다(Parke \& Bhavnagri, 1989). 따라서 자녀가 또래와 만나고 상호작용할 수 있도록 환경을 선택하고 또래를 집으로 초대하여 상호작용의 기회를 만들어 주면서 놀이 상황을 구조화해주는 방법은 유아가 친구관계를 형성하고 유지하는데 긍정적인 영향을 미칠 수 있다. 이 외에 도 어머니는 자녀가 어디에서 놀고 있는지, 무슨 활동을 하고 있는지에 대해서 인식하거나 알고 있는 형태로 감독하기도 하 고(Ladd \& Pettit, 2002), 자녀에게 또래관계에 대한 조언을 해 주거나 또래와의 관계에서 일어날 수 있는 다양한 상황에 대 해 이야기를 나누는 상담자 역할을 하기도 한다(Ladd \& Pettit, 2002).

이와 관련된 선행연구는 대부분 유아의 사회적 유능감이나 또래 수용도와 관련된 연구로서 친구관계에 대한 관련성을 유 추해볼 수 있다. 어머니가 자녀에게 또래 접촉의 기회를 자주 마련해주거나 또래와 어떻게 지내는지를 지속적으로 지켜볼 수록 또래로부터 수용되고(Hwang \& Moon, 2010), 또래 유능 성이 높은 것으로 나타났다(J. Y. Lee, Kang, \& Lee, 2009; J. H. Park, 2001). 어머니와 또래 관계에 대한 대화를 자주 참여할수 록 유아는 또래에게 인기가 있었고 교사에게 사회적 유능감이
높다고 평가되었다(Laird, Pettit, Mize, Brown, \& Linsey, 1994).

자녀의 친구관계에 대한 어머니의 관여는 어떻게 관여하는 지의 방식에 따라 유아에게 미치는 영향력이 상이하다는 연구 결과가 보고되었다. Hwang과 Moon (2010)에 의하면 자녀의 또래 관계에 대한 어머니의 조언 · 관심 행동은 유아의 또래 유 능성과 관련이 없고 중개·감독 행동만 긍정적인 영향을 미쳤 다. 어머니가 또래 관계에 대한 조언 - 관심을 많이 보이는 유 아일수록 또래 유능성이 낮다고 평가되거나(J. Y. Lee, Kang, \& Lee, 2009) 또래들에게 놀이 방해를 더 많이 한다는 결과를 보 이기도 했다(I. H. Kim \& Kim, 2017).

이상을 요약해보면, 어머니가 자녀에게 또래와 만날 기회 를 만들어 주고, 또래와 어떻게 놀이하는지 지켜보며 관리해 주거나 또래관계에 대해 함께 이야기를 나누며 조언해주는 것 은 유아가 친구관계를 형성하고 유지하는데 긍정적인 요인이 될 수 있다. 시간이 지나면서 유아의 친구관계에 관여하는 어 머니의 역할에 변화가 있는지, 그리고 어머니의 관여가 유아 의 친구관계 변화 유형에도 영향을 미치는지 살펴보는 것은 유아기 친구 관계의 안정성 및 변화를 이해하기 위해 매우 중 요하지만 이를 살펴본 연구는 별로 없다.

그러므로 본 연구에서는 유아의 정서 조절과 어머니의 친 구관계 관여가 5 개월 동안 변화하는지 그리고 이러한 변인들 이 단기 종단적으로 친구관계의 변화에 어떤 영향을 미치는지 파악하고자 하였다. 본 연구의 결과는 유아기 친구관계의 발 달적 특성을 이해하는데 도움을 줄 수 있을 것이다. 이를 통해 유아가 원만한 친구관계를 형성하고 건강한 심리사회적 발달 을 하기 위한 지도 방법과 임상 현장에서 중재 프로그램개발 에 필요한 기초 자료를 제공하는데 본 연구의 의의가 있다.

본 연구에서는 다음과 같은 연구 문제를 설정하였다.

\section{연구문제 1}

단기 종단적 친구관계의 변화 유형에 따라 유아의 정서 조절과 어머니의 친구관계 관여의 일반적 경향은 어떠한가?

\section{연구문제 2}

친구관계의 변화 유형에 따라 유아의 정서 조절과 어머니의 친구관계 관여의 변화는 차이가 있는가?

\section{연구문제 3}

유아의 정서 조절과 어머니의 친구관계 관여는 친구관계의 변화 유형에 어떤 영향을 미치는가? 


\section{연구방법}

\section{연구대상}

본 연구의 대상은 서울, 인천 및 경기도 지역에 소재한 7개의 유치원의 만 5 세반 18 개 학급에 재원하고 있는 유아들이었다. 연구 대상 유아들에게 5 개월의 시간 간격을 두고 2 회에 걸쳐 친구관계에 대한 자료를 수집하였는데 1 차와 2 차의 친구관계 자료가 모두 수집된 유아 중 275명(남아 137명, 여아 138명)이 최종 연구 대상으로 선정되었다. 연구 대상 유아의 평균 월령 은 1 차 자료 수집 시점을 기준으로 평균 70 개월이었다(표준편 차: 3.4 개월). 연구 대상을 선정하는 과정과 설문지의 회수 과 정은 연구 절차에 구체적으로 제시하였다.

\section{측정도구}

\section{친구관계}

유아의 친구관계에 관한 자료를 수집하기 위해 7월과 12 월 중 순에 5 개월 간격으로 총 2회 또래 지명법을 유아에게 실시하 였다. 또래 지명법은 친구관계를 알아보기 위해 주로 사용되 는 방법이다(Linsey, 2002; Rubin et al., 2006; Shin, Kim, Goetz, \& Vaughn, 2014).

면접자는 독립된 공간에서 각 유아에게 개별적으로 유아 자신이 속한 학급의 모든 동성 유아의 사진을 보여준 후 "가 장 친한 친구”를 3 명 지명하도록 하였다. 본 연구에서는 두 명 의 유아가 서로를 친구라고 상호 지명하였을 경우에 친구관 계로 간주하였다. 1 차 측정 후 5 개월 이후에 반복 측정하여 총 2 회 조사한 후, 상호 지명한 친구가 있는지와 동일한 친구 가 재지명 되었는지에 따라 친구관계의 변화를 '동일한 친구 지속 집단(same stable group)', '교체한 친구 지속 집단(different stable group), '친구 형성 집단(gain group)', '친구 상실 집단(loss group)', '친구관계 형성 불가 집단(chronically friendless group)' 의 5가지 유형으로 구분하였다(M. H. Park \& Park, 2016; Proulx \& Poulin, 2013; Bowker, Rubin, Burgess, Booth-LaForce, $\&$ Rose-Krasnor, 2006).

\section{정서 조절}

유아의 정서 조절 능력은 Salovey와 Mayer (1990), Goleman (1995)의 연구를 토대로 B. N. Lee (1997)가 제작한 정서 지능
척도의 4개 하위 영역 중 '자기 정서 조절'과 '타인 정서 조절' 의 2 개 하위 척도를 사용하여 측정하였다. '자기 정서 조절'은 자신의 감정을 정확히 인식하고 그 감정이 타인에게 끼칠 영 향을 고려하며 스스로 인식한 자신의 감정을 적절하게 처리하 고 변화시킬 수 있는 능력으로 총 8 문항으로 구성되었다. '타 인 정서 조절'은 상대방의 감정을 잘 파악하여 그들의 기분에 맞추어 행동하고 대처할 수 있으며, 다른 사람의 기분이 나쁠 때는 그 기분을 바꾸어 주려고 애쓸 줄도 아는 능력으로 총 9 문항으로 구성되었다.

유아의 정서 조절 능력 측정을 위해 연구 대상 유아가 속 한 18 개 학급의 주 담임 교사에게 평정 척도 실시상의 유의점 을 설명해 주고 척도에 응답하도록 하였다. 유아의 담임교사 는 각 문항에 나타난 특성을 유아가 어느 정도 보이는지에 따 라 전혀 그렇지 않다(1점)에서 정말 그렇다(4점)까지의 4점 척 도로 평정하였다. 각 하위 영역별 점수가 높을수록 정서 조절 수준이 높은 것을 의미한다. 전체 문항에 대한 내적 합치도 계 수 Cronbach's $\alpha$ 는 .90이였고, 각 하위 영역별 내적 합치도 계 수 Cronbach's $\alpha$ 는 자기 정서 조절이 .71, 타인 정서 조절이 .81 이었다.

\section{어머니의 친구관계 관여}

어머니가 유아의 친구관계를 위하여 어떠한 노력을 기울이는 지를 측정하기 위하여 J. H. Park (2001)이 번안한 Cohen (1989) 의 Parental Involvement Checklist [PIC]를 본 연구에 맞게 수정 하여 사용하였다. 이 질문지는 유아의 어머니가 평정하는 도 구로서, ‘조언 · 관심'(12문항)과 ‘중개· 감독'(12문항)의 하위 유형으로 구성되어 있고 총 24문항으로 이루어져 있다.

원 도구의 문항 중 요인 부하량이 낮고( .35 미만) 2 개의 하 위 영역에 비슷한 요인 부하량을 갖고 있는 2개의 문항과(“4. 아이의 친구관계에 대해 남편과 상의한다.", "17. 아이가 친 구와 놀 수 있도록 해주기 위해 가족의 계획을 바꾼다.”), 발 달적 특성을 고려했을 때 유아기에는 관찰하기 어려워 예비 조사에서 어머니들이 관찰할 수 없다고 보고한 1 개의 문항을 (20. 어떤 친구가 내 아이에게 전화를 거는지 파악한다) 제외 한 후, 본 연구에서는 '조언 · 관심' 11 문항, '중개·감독' 10 문 항을 사용하였다. 유아의 어머니가 자녀의 친구관계 발달을 촉진하기 위하여 각 문항에 적혀있는 행동을 얼마나 자주 했 는지에 대해 '전혀 안함(1점)'부터 ' 1 주일에 여러 번(6점)'까지 6점 척도에 응답하도록 하였다. 점수가 높을수록 유아의 친 구관계를 향상시키기 위한 노력을 많이 하였음을 의미한다. 
전체 문항에 대한 내적 합치도 계수 Cronbach's $\alpha$ 는 .89였고, 하위 영역별 Cronbach's $\alpha$ 는 ‘조언 · 관심'이 .89, ‘중개·감독' 이 88 이였다.

\section{연구 절차 및 분석}

유치원 2곳의 만 5세 유아 55명을 대상으로 예비 조사를 실시 하여 또래 지명법을 잘 이해하는지, 얼마간의 시간이 소요되 는지 알아보았고, 어머니와 교사들은 질문지를 이해하고 체 크하는데 어려움이 있는지 등을 조사하였다. 예비 조사 결과 를 바탕으로 질문지를 수정, 보완한 후 2013년 7월 중순에 1차 조사를 실시하였다. 1 차 조사에서는 본 연구자가 547 명의 유 아를 대상으로 또래지명법을 실시하여 친구관계를 조사하였 다. 2 차 조사는 본 연구자와 대학원 석 - 박사과정 재학 중인 5 명이 1차 조사와 동일한 절차에 의해 2013년 12월 중순에 501 명의 유아를 대상으로 또래지명법을 실시하였다. 또래 지명법 측정에 앞서 사전 훈련을 통해 본 연구자가 보조 연구자 4 명에 게 또래 평정 척도를 실시하는 방법과 절차를 주지하도록 하 였다. 또래 지명법에 대한 구체적인 절차는 M. H. Park과 Park (2015)의 연구 절차를 참고할 수 있다.

교사의 유아 정서 조절 질문지는 교사에게 평정을 의뢰 한 후 1 주일 후에 연구자가 수거하였다. 설문에 참여한 교사 는 1 차 시기에 19 명, 2 차 시기에는 전근 간 교사를 제외한 18 명이였다. 어머니의 친구관계 관여는 각 학급의 담임교사에 게 질문지를 배부하여 유아를 통해 어머니에게 전달하고 연 구자가 1 주일 후에 유치원을 방문하여 설문지를 수거하였다. 어머니 설문지는 1 차 조사에서 547 부 중 351 부가 회수되어 $64 \%$ 의 회수율을, 2 차 조사에서는 501 부 중 354 부로 $70 \%$ 의 회수율을 보였다. 1차와 2차 모두 회수된 어머니용 설문지는 모두 280 부였고 수거된 자료에서 설문지 문항에 반 이상을 평정하지 않은 설문지를 제외하고 275 부가 최종 분석에 활용 되었다.

본 연구에서 수집된 자료는 SPSS 20.0 프로그램을 사용하 여 친구관계의 변화 유형에 따른 집단의 일반적인 경향을 살 펴보기 위해 1,2 차 시기의 유아 정서 조절과 어머니의 친구관 계 관여에 대한 평균, 표준편차를 실시하였으며 시간의 흐름 에 따른 점수 변화가 있는지 알아보기 위해 $t$ 검증을 하였다. 또한 유아의 정서 조절 그리고 어머니의 친구관계 관여가 친 구관계의 변화 유형 집단에 영향을 미치는지를 알아보기 위해 다중 로지스틱 회귀분석을 실시하였다.

\section{연구 결과}

\section{친구관계의 변화 유형에 따라 유아의 정서 조 절과 어머니의 친구관계 관여의 일반적 경향}

친구관계의 변화 유형에 따라 유아의 정서 조절과 어머니의 친구관계 관여에 대한 평균과 표준편차를 분석하였으며 그 결 과는 Table 1 에 제시하였다.

정서 조절의 하위 요인 중 자기 정서 조절은 1 차와 2 차에서 모두 동일한 친구 지속 집단이 높고 $(M=2.94,2.95)$ 친구 형성 불가 집단 $(M=2.71,2.73)$ 이 낮았다. 타인 정서 조절은 1 차와 2 차에서 모두 동일한 친구 지속 집단이 높고 $(M=3.17,3.32)$ 친 구 형성 불가 집단이 낮았다 $(M=2.74,2.97)$.

어머니의 친구관계 관여를 살펴보면, 조언·관심이 가장 높 은 집단은 1,2 차 시기 모두 교체한 친구 지속 집단 이었다 $(M$ $=4.61,4.47)$. 조언.관심이 가장 낮은 집단은 1 차 시 동일한 친 구 지속 집단 $(M=4.07), 2$ 차 시 친구 형성 불가 집단이었다 $(M$ $=4.04)$.

\section{친구관계의 변화 유형에 따라 유아의 정서 조절과 어머니의 친구관계 관여 변화의 차이}

친구관계의 변화 유형에 따라 유아의 정서 조절과 어머니의 친구관계 관여의 변화가 차이가 있는지를 살펴보기 위해 각 집단별로 1,2 차 시기의 평균에 대해 $t$ 검증을 실시하였고 그 결과를 Table 1 에 제시하였다.

1 차에서 2 차까지 5 개월 동안 유아의 정서 조절 중 자기 정 서 조절은 모든 집단에서 5 개월 간 유의한 증가를 보이지 않았 다. 타인 정서 조절은 모든 친구관계의 변화 유형에서 유의하 게 증가하였다.

어머니의 친구관계 관여는 친구 형성 불가 집단만 중개·감 독 $(t=2.13)$ 과 조언 · 관심 $(t=2.17)$ 이 1 차에서 2 차까지 5 개월 동안 유의하게 감소하였다.

\section{유아의 정서 조절과 어머니의 친구관계 관여가 친구관계의 변화 유형에 미치는 영향}

유아의 정서 조절과 어머니의 친구관계 관여가 친구관계의 변 화유형에 영향을 미치는지 알아보기 위하여 친구관계의 변 화 유형을 종속변인으로 하고 첫 번째 시기에 측정한 유아의 정서 조절과 어머니의 친구관계 관여를 독립변인으로 하는 
Table 1

Means, Standard Deviations, and Comparison of Friendship Patterns over Time 1 and Time 2

\begin{tabular}{|c|c|c|c|c|c|c|c|c|c|c|}
\hline \multirow[b]{2}{*}{ Friendship patterns } & \multicolumn{2}{|c|}{$\begin{array}{l}\text { Same-stable } \\
\text { friendships } \\
(n=120)\end{array}$} & \multicolumn{2}{|c|}{$\begin{array}{l}\text { Different-stable } \\
\text { friendships } \\
(n=50)\end{array}$} & \multicolumn{2}{|c|}{$\begin{array}{l}\text { Gain } \\
\text { friendship } \\
(n=44)\end{array}$} & \multicolumn{2}{|c|}{$\begin{array}{c}\text { Loss } \\
\text { friendship } \\
(n=25)\end{array}$} & \multicolumn{2}{|c|}{$\begin{array}{c}\text { Chronically } \\
\text { friendless } \\
(n=36)\end{array}$} \\
\hline & $\begin{array}{c}M \\
(S D)\end{array}$ & $\begin{array}{c}M \\
(S D)\end{array}$ & $\begin{array}{c}M \\
(S D)\end{array}$ & $\begin{array}{c}M \\
(S D)\end{array}$ & $\begin{array}{c}M \\
(S D)\end{array}$ & $\begin{array}{c}M \\
(S D)\end{array}$ & $\begin{array}{c}M \\
(S D)\end{array}$ & $\begin{array}{c}M \\
(S D)\end{array}$ & $\begin{array}{c}M \\
(S D)\end{array}$ & $\begin{array}{c}M \\
(S D)\end{array}$ \\
\hline \multicolumn{11}{|l|}{ Emotion Regulation } \\
\hline Self-regulation & \multicolumn{2}{|c|}{$t=-.53$} & \multicolumn{2}{|c|}{$t=.30$} & \multicolumn{2}{|c|}{$t=.12$} & \multicolumn{2}{|c|}{$t=.88$} & \multicolumn{2}{|c|}{$t=-.49$} \\
\hline \multirow[t]{2}{*}{ Other-regulation } & $\begin{array}{l}3.17 \\
(.46)\end{array}$ & $\begin{array}{l}3.32 \\
(.49)\end{array}$ & $\begin{array}{l}3.15 \\
(.48)\end{array}$ & $\begin{array}{l}3.29 \\
(.47)\end{array}$ & $\begin{array}{l}3.09 \\
(.49)\end{array}$ & $\begin{array}{l}3.25 \\
(.56)\end{array}$ & $\begin{array}{l}3.01 \\
(.54)\end{array}$ & $\begin{array}{l}3.22 \\
(.45)\end{array}$ & $\begin{array}{l}2.74 \\
(.53)\end{array}$ & $\begin{array}{l}2.97 \\
(.52)\end{array}$ \\
\hline & \multicolumn{2}{|c|}{$t=-6.38^{* * *}$} & \multicolumn{2}{|c|}{$t=-2.83^{* * *}$} & \multicolumn{2}{|c|}{$t=-3.12^{* * *}$} & \multicolumn{2}{|c|}{$t=-2.90^{* * *}$} & \multicolumn{2}{|c|}{$t=-2.79^{* * *}$} \\
\hline $\begin{array}{l}\text { Advice-support } \\
\text { strategies }\end{array}$ & \multicolumn{2}{|c|}{$t=-.26$} & \multicolumn{2}{|c|}{$t=1.00$} & \multicolumn{2}{|c|}{$t=.57$} & \multicolumn{2}{|c|}{$t=.22$} & \multicolumn{2}{|c|}{$t=2.17^{*}$} \\
\hline \multirow{2}{*}{$\begin{array}{l}\text { Mediation- } \\
\text { supervision } \\
\text { strategies }\end{array}$} & $\begin{array}{c}3.20 \\
(1.03)\end{array}$ & $\begin{array}{c}3.11 \\
(1.06)\end{array}$ & $\begin{array}{c}3.41 \\
(1.10)\end{array}$ & $\begin{array}{c}3.32 \\
(1.20)\end{array}$ & $\begin{array}{c}3.52 \\
(1.01)\end{array}$ & $\begin{array}{c}3.27 \\
(1.17)\end{array}$ & $\begin{array}{c}3.25 \\
(1.08)\end{array}$ & $\begin{array}{c}3.05 \\
(1.08)\end{array}$ & $\begin{array}{c}2.98 \\
(1.05)\end{array}$ & $\begin{array}{c}2.56 \\
(1.02)\end{array}$ \\
\hline & \multicolumn{2}{|c|}{$t=.18$} & \multicolumn{2}{|c|}{$t=1.12$} & \multicolumn{2}{|c|}{$t=1.17$} & \multicolumn{2}{|c|}{$t=1.49$} & \multicolumn{2}{|c|}{$t=2.13^{*}$} \\
\hline
\end{tabular}

Note. $N=275$.

${ }^{*} p<.05 .{ }^{* *} p<.01 .{ }^{* * *} p<.001$.

다항로지스틱 회귀분석을 실시하였다. 친구관계의 변화 유 형 집단을 하나씩 참조 범주로 설정하여 다른 집단과 상대적 비교를 하였고 이에 대한 회귀계수 $(B)$ 추정값과 참조 범주 대 비 승산비(Odds Ratios: OR)를 Table 2에 제시하였다. 분석 결 과, Naglkerke의 $\mathrm{R}^{2}$ 은 . 15 였는데 이는 본 회귀모델이 종속변 인 변량의 $15 \%$ 를 설명해 주는 것이라고 할 수 있다. 모형의 적절성을 살펴본 결과, 기저 모형 대비 분석 모형의 카이자승 값의 차이가 $\left(\chi^{2}(16)=42.55, p<.001\right)$ 유의미하게 나타났다. 이는 분석모형의 적합도가 기저모형보다 유의미하게 좋아진 것을 의미하므로 본 연구에서 설정한 모형은 양호하다고 할 수 있다.

먼저 친구관계의 변화 유형 중 친구 형성 불가 집단을 참조 범주로 설정하여, 자기 정서 조절이 친구관계의 변화 유형을 예측하는 상대적 차이를 비교한 결과는 유의하지 않았다. 타 인 정서 조절이 친구관계의 변화 유형을 예측하는 상대적 차이 를 비교한 결과, 타인 정서 조절이 한 단위씩 증가할수록 친구 형성 불가 집단일 가능성보다 동일한 친구 지속 집단일 가능 성이 6.5 배 $(\mathrm{OR}=6.49, p<.05)$, 교체한 친구 지속 집단일 가능 성이 6.1 배 $(\mathrm{OR}=6.11, p<.05)$, 친구 형성 집단일 가능성이 2.9 배 $(\mathrm{OR}=2.93, p<.05)$, 친구 상실 집단일 가능성이 1.2 배 $(\mathrm{OR}=$
$1.18, p<.05)$ 증가하였다. 어머니의 친구관계 관여의 하위요인 중 조언·관심이 친구관계의 변화 유형을 예측하는 상대적 차 이를 비교한 결과는 유의하지 않았다. 중개·감독이 한 단위씩 증가할수록 친구 형성 불가 집단일 가능성보다 친구 형성 집단 일 가능성이 1.8 배 $(\mathrm{OR}=1.77, p<.05)$ 증가하였다.

친구 상실 집단을 준거 집단으로 설정하여 유아의 정서 조 절과 어머니의 친구관계 관여가 친구관계의 변화 유형을 예측 할 상대적 차이를 비교한 결과는 유의하지 않았다. 친구 형성 집단을 참조 범주로 설정하여 다른 집단과 상대적 차이를 비 교한 결과, 정서 조절은 친구관계의 변화 유형을 예측하는 데 유의하지 않았다. 어머니의 친구관계 관여는 하위 요인 중 조 언 · 관심이 한 단위 증가할수록 친구 형성 집단보다 교체한 친 구 지속 집단일 가능성이 1.8 배 $(\mathrm{OR}=1.81, p<.05)$ 높아지는 것으로 나타났다. 중개·감독은 친구관계의 변화 유형을 예측 하는데 유의하지 않았다.

교체한 친구 지속 집단을 참조 범주로 설정하여 동일한 친 구 지속 집단과 비교한 결과. 정서 조절은 친구관계의 변화 유 형을 예측하는 데 유의하지 않았다. 어머니의 친구관계 관여 는 조언 · 관심이 한 단위 증가할수록 교체한 친구 지속 집단 일 가능성보다 동일한 친구 지속 집단일 가능성이 0.5 배 $(\mathrm{OR}=$ 
Table 2

Logistic Regression Analysis of Emotion Regulation and Parental Involvement on Friendship Patterns

\begin{tabular}{|c|c|c|c|c|c|c|c|c|c|c|c|c|c|c|c|c|c|c|c|c|}
\hline \multirow{3}{*}{$\begin{array}{l}\begin{array}{r}\text { Dependent } \\
\text { variable }\end{array} \\
\text { Independent } \\
\text { variable }\end{array}$} & \multicolumn{8}{|c|}{ Friendless (Ref.) } & \multicolumn{6}{|c|}{ Loss (Ref.) } & \multicolumn{4}{|c|}{ Gain (Ref.) } & \multirow{2}{*}{\multicolumn{2}{|c|}{$\begin{array}{c}\begin{array}{c}\text { Different- } \\
\text { stable (Ref.) }\end{array} \\
\begin{array}{c}\text { Same- } \\
\text { stable }\end{array}\end{array}$}} \\
\hline & \multicolumn{2}{|c|}{$\begin{array}{l}\text { Same- } \\
\text { stable }\end{array}$} & \multicolumn{2}{|c|}{$\begin{array}{l}\text { Different- } \\
\text { stable }\end{array}$} & \multicolumn{2}{|c|}{ Gain } & \multicolumn{2}{|c|}{ Loss } & \multicolumn{2}{|c|}{$\begin{array}{l}\text { Same- } \\
\text { stable }\end{array}$} & \multicolumn{2}{|c|}{$\begin{array}{l}\text { Different- } \\
\text { stable }\end{array}$} & \multicolumn{2}{|c|}{ Gain } & \multicolumn{2}{|c|}{$\begin{array}{l}\text { Same- } \\
\text { stable }\end{array}$} & \multicolumn{2}{|c|}{$\begin{array}{c}\text { Different- } \\
\text { stable }\end{array}$} & & \\
\hline & $B$ & OR & $B$ & OR & $B$ & OR & $B$ & OR & $B$ & OR & $B$ & OR & $B$ & OR & $B$ & OR & $B$ & OR & $B$ & OR \\
\hline \multicolumn{21}{|l|}{$\begin{array}{l}\text { Emotion } \\
\text { Regulation }\end{array}$} \\
\hline $\begin{array}{l}\text { Other- } \\
\text { regulation }\end{array}$ & $1.87^{*}$ & 6.49 & $1.81^{*}$ & 6.11 & $1.08^{*}$ & 2.93 & $.16^{*}$ & 1.18 & .05 & 1.05 & .05 & 1.05 & .02 & 1.02 & .03 & 1.03 & .03 & 1.03 & -.00 & 1.00 \\
\hline \multicolumn{21}{|l|}{$\begin{array}{l}\text { Parental } \\
\text { Involvement }\end{array}$} \\
\hline $\begin{array}{l}\text { Advice-support } \\
\text { strategies }\end{array}$ & -.25 & .78 & .37 & 1.45 & -.22 & .80 & .00 & 1.00 & -.25 & .78 & .37 & 1.44 & -.22 & .80 & -.02 & .98 & $.59^{*}$ & 1.81 & $-.61^{*}$ & .54 \\
\hline
\end{tabular}

Note. $N=275$.

Ref. $=$ reference group. -2 Log Likelihood $=736.88\left(\chi^{2}=42.55^{* * *}\right)$, Nagelkerke $\mathrm{R}^{2}=.15$.

${ }^{*} p<.05 .{ }^{* * *} p<.001$.

$.54, p<.05)$ 낮아졌다.

이상의 분석 결과를 요약해 보면, 정서 조절 영역 중 타인 정서 조절 능력이 증가할수록 유아는 5개월 후에 친구 형성 불 가 집단보다는 동일한 친구 지속 집단, 교체한 친구 지속 집단, 친구 형성 집단, 친구 상실 집단에 소속될 가능성이 높다는 것 을 의미한다. 또한 어머니의 친구관계 관여 중 중개·감독이 증가할수록 유아는 친구 형성 불가 집단보다는 친구 형성 집 단에 소속될 가능성이 높음을 의미하고 조언·관심이 증가할 수록 유아는 친구 형성 집단보다 교체한 친구 지속 집단에 소 속될 가능성, 동일한 친구 지속 집단에 비해 교체한 친구 지속 집단에 소속될 가능성이 높음을 의미한다.

\section{논의 및 결론}

본 연구에서는 만 5 세 유아의 친구관계와 정서 조절, 어머니의 친구관계 관여를 5 개월 간격으로 2 회 반복 측정하여 시간의 흐름에 따른 변화를 살펴보고, 유아의 정서조절과 어머니의 친구관계 관여가 친구관계의 변화유형에 어떤 영향을 미치는 지 분석하였다.

대부분의 유아들은 5 개월 동안 정서 조절의 하위 요인 중 타인정서 조절 능력이 증가하였다. 이는 유아가 연령이 증가
함에 따라 정서를 이해하는 능력이 향상되고 정서를 조절 하 는데 사용할 수 있는 인지적 책략이 다양해지기 때문에 사회 적 상황에서 적절하게 대응할 수 있게 된다(Rose-Krasnor \& Denham, 2009; Rubin, et al., 2006)는 발달적 변화를 나타낸 결 과로 해석될 수 있다. 이러한 해석은 정서적 반응을 유발하는 상황에서 3,4 세는 울거나 가만히 있는 등의 내면화 반응과 모 른다거나 무응답 등의 비해결 반응을 많이 보였는데 5 세는 문 제 상황을 바꾸려 하는 전략과 실질적 도움 제공하기 같은 문 제해결전략을 주로 사용하였다는 선행연구에 의해(W. Y. Park $\& \mathrm{An}, 2006)$ 뒷받침될 수 있다.

한편 5개월에 걸친 기간 동안 친구가 계속 없는 유아의 어 머니는 1 차 에 비해 2 차 시기에 자녀의 또래관계에 관심을 갖 고 조언을 해주는 행동과 또래를 만날 수 있도록 중개하고 감 독하는 정도가 유의하게 줄어드는 것을 보여주고 있었다. 이 는 아동 효과 관점(Child-effects perspective; Ladd \& Pettit, 2002) 을 지지하는 결과로도 해석해 볼 수 있다. 즉 사회적 유능감이 높은 유아는 어머니에게 또래와 만날 기회를 더 많이 만들어 달라고 요구하고 친구관계에 대해 이야기하기를 원한다. 반면 에 사회적 유능감이 낮은 유아는 또래와 만나는 기회에 대한 요구도 적고 또래와의 상호작용에 있어 어머니의 참여를 제한 시킨다. 즉 계속 친구가 없는 유아는 스스로 자신의 사회적 참 여와 친구관계에 대한 요구와 이야기를 덜 요구하여 어머니의 
친구관계를 촉진하는 행동이 줄어들었을 것으로 유추해 볼 수 있다. 그러나 본 연구는 친구가 계속 없는 유아의 사회적 유능 성을 직접 측정해 보지 않았으므로 추후 연구에서 더 확인해 보아야 할 필요가 있다.

유아의 정서조절과 어머니의 친구관계 관여가 친구관계의 변화 유형에 미치는 영향을 친구관계의 변화 유형별로 준거 집단을 설정하여 비교한 결과, 타인 정서조절을 잘 할수록 친 구 형성 불가 집단에 비해 동일한 친구 지속 집단, 교체한 친 구 지속 집단, 친구 형성 집단, 친구 상실 집단일 가능성이 높 았다. 이는 유아가 상대방의 감정을 잘 파악하여 그에 맞게 행 동하고 대처하는 능력이 향상될수록 5개월 동안 한 번이라 도 친구가 있거나 계속 친구가 있을 가능성이 높아질 수 있음 을 나타낸다. 이는 유아가 정서조절을 잘 할수록 또래에게 인 기가 있고 사회적 유능감이 높으며 친구가 있다는 선행연구 들(Blair, Denham, Kochanoff, \& Whipple, 2004; Denham et al., 2003; Walden, Lemerise, \& Smith, 1999)과 유사한 결과였다. 친 구는 두 명의 관계에서 이루어지는 상호작용이므로 이러한 사 회적 상호작용을 유지하기 위해서는 정서를 조절해야 하는 경 우가 많이 생길 수 있다. 본 연구의 결과는 또래와 상호작용할 때 자신과 상대방의 정서를 이해하고 적절하게 조절하여 대처 하는 능력이 유아의 친구 관계에서도 중요한 사회적 기술임을 제시해 주고 있다.

Eivers 등(2012)은 유아의 친구관계를 12 개월 후에 반복 조 사하였다. 두 시기 모두 친구가 없었던 유아는 공격성의 증가 를 보이지는 않았으나 다른 또래들에 비해 친사회성이 증가하 지 않았다. McElwain, Halberstadt와 Volling (2007)의 연구에서 는 예상 밖의 실망스러운 보상을 받았을 때 자신의 정서를 조 절하는 수준만으로는 친구간의 긍정적 상호작용과 관련이 없 었으나, 타인의 정서를 이해하고 공감하며 지지해주는 능력 도 같이 높은 수준일 때 또래와 긍정적인 상호작용을 많이 하 였고 갈등 수준도 낮은 것으로 나타났다. 이처럼 유아가 친구 를 사귀거나 관계를 유지하기 위해서는 상대방을 때리거나 위 협을 가하는 등 공격적인 행동을 하지 않는 것 이상으로 다른 사람의 기분이 어떤지 정확하게 인지하고 그 추측을 바탕으로 상대방의 기분을 바꾸어 주려고 노력하거나 자신의 행동을 조 율하는 타인 정서 조절이 친구관계를 형성하는데 필요한 능력 임을 시사한다.

정서 조절의 하위요인인 자기 정서 조절은 친구관계 변화 유형을 예측하지 못했다. 이는 다음과 같이 해석해 볼 수 있 다. 유아가 또래와 친구를 대하는 태도가 다를 수 있는데, 보 통 때에는 화를 잘 내는 유아가 친구에게는 자신의 부정적인
정서를 참기도 하면서 상호작용을 해서 새롭게 친구를 사귀 거나 계속 친구가 있었을 수 있다. 유아는 보통 또래와 상호 작용 할 때 보다 친구와 상호작용할 때 화내고 흥분하며 불 평하는 행동을 적게 하였다는 선행연구 결과가(Salvas, Vitaro,

Brendgen, Lacourse, Boivin, \& Tremblay, 2011) 이러한 해석을 뒷받침해 준다.

또는 다음과 같이 해석해볼 수도 있다. 본 도구에서 사용 한 정서조절의 하위요인 중 자기 정서조절을 측정하는 문항 들은 대부분 '화’를 잘 참는지를 평정하도록 구성되어 있다. 그 러나 사람의 마음에 일어나는 감정에는 '화' 이외에도 슬픔, 실 망, 두려움과 같은 감정들이 있고 기쁨이나 행복감 같은 정적 정서도 포함되어 있다. Spinrad 등(2004)의 연구에 따르면 두 려움을 적절하게 조절하지 못하고 위축되거나 과도하게 억제 되는 유아는 주로 혼자 놀이했고 또래들에게 소외당했다. 또 한 우울한 유아는 또래에게 인기가 없고 거부와 괴롭힘을 당 할 가능성이 높았으며, 슬픔을 자주 보이는 유아도 또래에게 무시당하는 경우가 많았다(Denham, McKinley, Counhoud, \& Holt, 1990). 이처럼 '화' 이외의 위축이나 두려움 같은 부적 정 서를 잘 조절하지 못하는 유아가 친구관계를 형성하지 못할 수 있는데 본 연구에서 사용한 측정 도구가 ‘화' 이외의 다른 부적 정서를 포함하지 않아 자기 정서조절능력이 친구와의 관 계에 미치는 영향이 잘 드러나지 않았을 수도 있다.

어머니의 친구관계 관여와 친구관계의 변화 유형과의 관련 성을 살펴보면, 어머니가 자녀의 친구관계에 대해 관심을 갖 고 이야기를 많이 나눌수록 유아는 친구 형성 집단에 비해 동 일한 유아는 아니지만 5 개월 동안 계속 친구가 있는 교체한 친 구 지속 집단에 속할 가능성이 높았다. 이러한 결과는 어머니 의 조언이 유아의 또래관계에 긍정적인 영향을 미칠 수 있다 고 보고한 선행연구(Laird, et al., 1994; Mize \& Pettit, 1997), 어 머니의 코칭이 다른 또래의 관계적 공격성으로부터 보호요 인이 될 수 있다는 선행연구와(Werner, Eaton, Lyle, Tseng, \& Holst, 2013) 유사한 맥락에서 이해될 수 있다.

유아는 어머니와 어떻게 친구관계를 형성하고 갈등을 해결 할지에 대해서 주로 이야기를 나눈다(Laird et al., 1994). 이때 어머니는 자녀의 친구관계에 대해서 관심을 기울이며 어떤 어 려움을 경험하고 있는지, 친구와 상호작용 중에 느끼는 감정 의 원인과 결과는 어떠한지 등에 대해 정서를 중심으로 한 대 화를 나눌 수 있다. 이러한 과정을 통해 유아는 부정적인 정서 를 수용 받고 여러 가지 갈등 해결 전략을 탐색해봄으로써 친 구관계를 형성하는데 필요한 다양한 문제 해결 전략을 습득하 고 친구를 사귈 수 있었을 것이다. 어머니가 유아기 자녀와 또 
래 간에 발생하는 갈등에 대해서 대화를 나눌 때 부정적인 정 서를 수용해주고 문제의 인과 관계를 언어로 정교화해줄 경우 유아는 관계적 공격성을 당할 가능성이 낮았다거나(Werner, et al., 2013), 타인의 정서를 잘 이해하고 친구간의 협동놀이에서 도 갈등이 적었다고 밝힌 선행연구(McElwain et al., 2007)가 이 를 뒷받침한다.

그리고 어머니의 친구관계 관여의 하위 요인 중 어머니의 중개 · 감독이 증가할수록 5개월 이후에 친구 형성 불가 집단 보다 친구 형성 집단일 가능성이 높았다. 이는 어머니가 자녀 를 또래와 만날 수 있도록 기회를 제공해 주고 또래와의 상호 작용을 관심있게 지켜봐줄수록 유아는 5개월 후 새롭게 친구 관계를 형성하게 될 가능성이 높음을 의미한다. 이러한 연구 결과는 어머니가 또래와 만나서 상호작용할 수 있는 기회를 마련해주고 또래 간의 갈등 관계를 조절하고 감독하는 어머니 의 노력이 유아의 또래관계에 긍정적인 영향을 미친다는 선행 연구 결과(J. S. Kim, 2011; Ladd \& Hart, 1992)와 일치한다. 또 래와 함께 놀 수 있도록 구조화 시켜주는 노력은 '교제'를 경험 할 수 있도록 기회를 주는 것이다. 또래를 만날 기회를 많이 경 험한 유아는 상호작용할 기회가 많아지게 되면서 또래와 같 은 활동에 참여하게 되고 의사소통을 주고받으며 놀이의 즐거 움이 증대되고 친밀감이 높아져서 친한 친구관계를 형성할 수 있었을 것으로 간주된다.

그러나 어머니의 친구관계 관여에 대한 해석은 주의를 기 울일 필요가 있다. 본 연구에서는 친구가 없었지만 어머니가 친구관계를 중개하고 감독해주면 5 개월 후에 친구가 생길 가 능성이 1.8 배 높았다. 이에 비해 유아의 타인조절 능력이 높아 지면 친구가 생길 가능성은 2.9 배, 동일한 친구와 계속 친구가 될 가능성은 6.5 배 높았다. 친구관계 유형별 집단의 일반적 경 향을 분석한 결과에서도 동일한 친구 관계를 지속하는 유아의 부모는 높은 친구관계 관여 수준을 보이지 않았다. 이러한 결 과는 부모의 적극적인 노력이 친구가 없는 유아에게 친구를 사귀도록 하는 데는 도움이 될 수 있으나 친밀한 관계를 유지 하는데는 큰 영향을 미치지 않을 수 있음을 의미한다. 최근 유 아의 사회적 유능성이 중요하다는 인식이 증가하면서 어머니 들이 자녀의 사회성 발달에 도움이 될 것이라고 기대해서 어 린 유아를 이른 시기부터 유아교육기관에 다니게 하거나 방과 후에도 키즈 카페 등에서 또래들과 사적으로 만나게 해주는 경우가 종종 있다. 본 연구의 결과는 친구 관계를 형성하고 유 지하는 대인관계에서의 유능성은 자녀의 친구 관계에 관여하 는 부모의 행동 같은 외부적인 요인보다 타인을 이해하고 자 신의 행동을 조절할 수 있는 능력인 개인 내적인 변인이 중요
하다는 것을 보여주고 있다. 그러므로 유아가 친구를 사귀고 원만하게 관계를 지속시키는 대인 관계적 유능성을 발달시키 기 위해서는 유아와 가정 내에서 놀이를 함께 하면서 편안하 게 자신의 생각과 느낌을 표현하게 하고 타인의 정서를 이해 하는 기회를 주면서 개인 내적인 역량을 강화시켜주는 과정이 중요할 것이다.

마지막으로 본 연구의 제한점을 제시하면서 동시에 후속 연구를 위한 제언을 하면 다음과 같다.

첫째, 선행연구는 친구 상실 집단 아동이 또래에게 괴롭힘 당할 가능성이 높아지고, 우울, 위축, 외로움과 같은 심리적 어 려움이 발생할 수 있으며(Bowker et al., 2006; Proulx \& Poulin, 2013 친구 형성 불가 집단과 유사한 특성을 나타낸다고 보 고하였다(Bowker et al., 2006). 또한 학령기 아동을 대상으로 한 연구에서는 동일한 친구 지속 집단과 교체한 친구 지속 집 단의 사회적 적응에 차이가 나타나지 않았으나 유아를 대상 으로 한 연구에서는 동일한 친구 지속 집단이 교체한 친구 지 속 집단에 비해 갈등을 해결하고 또래 간에 협력하는 사회적 기술이 더 뛰어나다고 보고했다(Bowker et al., 2006; Proulx \& Poulin, 2013). 추후 연구에서는 친구관계 유형의 변화에 따라 사회적 적응과 심리적 안녕감을 추적 조사하여 유아기 친구관 계의 변화 유형이 연령에 따라 다른 기능과 발달 경로를 보이 는지 이해할 필요가 있을 것이다. 둘째, 본 연구에서는 유아와 개별 면접을 통해 친구관계를 측정하였고 유아가 어떻게 친구 와 상호작용하고 놀이하는지는 관찰하지 않았다. 추후 연구에 서는 친구 쌍 유아의 상호작용 행동을 관찰하여 친구관계가 유지되거나 해체되는데 영향을 미치는 요인들을 살펴보는 것 이 필요하다.

본 연구에서는 단기 종단적으로 유아의 친구관계 변화 유 형과 관련 변인을 파악하였고, 유아가 친구관계를 형성하고 유지하는데 필요한 개인 내적인 요인으로 정서 조절 능력과 어머니가 유아의 친구관계에 관여하는 환경적 요인을 통합 적으로 살펴보았다는데 의의가 있다. 특히 본 연구 결과는 만성적으로 친구가 없는 유아를 대상으로 친구관계 발달을 촉진하도록 프로그램을 계획할 때, 유아에게는 타인 지향적 인 정서 조절 능력을 발달시킬 수 있는 중재 방법을 모색할 필요가 있고 어머니에게는 친구관계에 대한 질 높은 조언과 올바른 중개 및 감독을 포함시킬 필요가 있음을 시사해 주고 있다. 


\section{Notes}

This article is a part of the first author's doctoral dissertation submitted in 2015 .

\section{Conflict of Interest}

No potential conflict of interest relevant to this article was reported.

\section{References}

\section{In English}

Berndt, T. J., \& McCandless, M. A. (2009). Methods for investigating children's relationships with friends. In K. H. Rubin, W. M. Bukowski, \& B. Laursen (Eds.), Handbook of peer interactions, relationships, and groups (pp. 63-81). New York: The Guilford Press.

Blair, K. A., Denham, S. A., Kochanoff, A., \& Whipple, B. (2004). Playing it cool: Temperament, emotion regulation, and social behavior in preschoolers. Journal of School Psychology, 42(6), 419-443. doi: 10.1016/j.jsp.2004.10.002

Bowker, J. C. W., Rubin, K. H., Burgess, K. B., Booth-LaForce, C., \& Rose-Krasnor, L. (2006). Behavioral characteristics associated with stable and fluid best friendship patterns in middle childhood. Merrill-Palmer Quarterly, 52(4), 671693.

Bonnet, M., Goossens, F. A., \& Schuengel, C. (2011). Parental strategies and trajectories of peer victimization in 4 to 5year olds. Journal of school psychology, 49(4), 385-398. doi: 10.1016/j.jsp.2011.04.002

Bukowski, W. M., Buhrmester, D., \& Underwood, M. K. (2011). Peer relations as a developmental context. In M. K. Underwood, \& L. H. Rosen (Eds.), Social development: Relationships in infancy, childhood, and adolescence (pp. 153179). New York : Guilford Press.

Cillessen, A. H. N. (2009). Sociometric methods. In K. H. Rubin, W. M. Bukowski, \& B. Laursen (Eds.), Handbook of peer interactions, relationships, and groups (pp. 82-99). New York: The Guilford Press.

Cohen, J. S. (1989). Maternal involvement in children's peer relationships during middle childhood (Unpublisehd doctoral dissertation). University of Waterloo, Ontario, Canada.

Denham, S. A., Blair, K. A., DeMulder, E., Levitas, J., Sawyer,
K., Auerbach-Major, S., \& Queenan, P. (2003). Preschool emotional competence: Pathway to social competence. Child Development, 74(1), 238-256. doi:10.1111/14678624.00533

Denham, S. A., McKinley, M., Couchoud, E. A., \& Holt, R. (1990). Emotional and behavioral predictors of preschool peer ratings. Child Development, 61(4), 1145-1152. doi: $10.2307 / 1130882$

Eisenberg, N., Fabes, R. A., Murphy, B., Maszk, P., Smith, M., \& Karbon, (2008). The role of emotionality and regulation in children's social functioning: A Longitudinal study. Child Development, 66(5), 1360-1384. doi: 10.1111/j.14678624.1995.tb00940.x

Eivers, A. R., Brendgen, M., Vitaro, F., \& Borge, A. I. H. (2012). Concurrent and longitudinal links between children's and their friends' antisocial and prosocial behavior in preschool. Early Childhood Research Quarterly, 27(1), 137-146. doi:10.1016/j.ecresq.2011.05.001

Goleman, D. (1995). Emotional Intelligence. New York: Bantam Books.

Hay, D. F., Payne, A., \& Chadwick, A. (2004). Peer relations in childhood. Journal of Child Psychology and Psychiatry, 45(1), 84-108. doi:10.1046/j.0021-9630.2003.00308.x

Howes, C. (1990). Social status and friendship from kindergarten to third grade. Journal of Applied Developmental Psychology, 11(3), 321-330. doi: 10.1016/0193-3973(90)90013-A

Howes, C. (2009). Friendship in early childhood. In K. H. Rubin, W. M. Bukowski, \& B. Laursen (Eds.), Handbook of peer interactions, relationships, and groups (pp. 180-194). New York: The Guilford Press.

Keane, S. P. \& Calkins, S. D. (2004). Predicting kindergarten peer social status from toddler and preschool problem behavior. Journal of Abnormal Child Psychology, 32(4), 409-423. doi:10.1023/B:JACP.0000030294.11443.41

Ladd, G. W. \& Hart, C. H. (1992). Creating informal play opportunities: Are parent's and preschooler's initiations related to children's competence with peer? Developmental Psychology, 28(6), 1179-1187. doi: 10.1037/0012-1649. 28.6.1179

Ladd, G. W., Kochenderfer, B. J. \& Coleman, C. C. (1996). Friendship quality as a predictor of young children's early school adjustment. Child Development, 67(3), 1103-1118. doi:10.1111/j.1467-8624.1996.tb01785.x

Ladd, G. W. \& Pettit, G. S. (2002). Parenting and the development of children's peer relationships. In M. H. Borenstein (Ed..). Handbook of parenting Vol 5: Practical issue in parenting (2nd ed., pp. 269-309). Mahwah, NJ: Lawrence Erlbaum.

Laird, R. D., Pettit, G. S., Mize, J., Brown, E. G., \& Lindsey, E. (1994). Mother-child conversations about peers: Contributions to competence. Family Relations, 43(4), 425- 


\section{2. doi: $10.2307 / 585374$}

Lindsey, E. W. (2002). Preschool children's friendships and peer acceptance: Links to social competence. Child Study Journal, 32(3), 145-155.

McElwain, N. L., Halberstadt, A. G., \& Volling, B. L. (2007). Mother-and father reported reactions to children's negative emotions: Relations to young children's emotional understanding and friendship quality. Child Development, 78(5), 1407-1425. doi:10.1111/j.1467-8624.2007.01074.x

Mize, J., \& Petitt, G. S., (1997). Mothers' social coaching, motherchild relationship style, and children's peer competence: Is the medium the message? Child Development, 68(2), 291311, doi:10.1111/j.1467-8624.1997.tb01942.x

Parke, R. D., \& Bhavnagri, N. (1989) Parents as managers of Children's social relationships. In D. Belle. (Ed). Children's social networks and social supports (pp. 241-259). New York: John Wiley \& Sons.

Parke, R. D., Simpkins, S. D., McDowell, D. J., Kim, M., Killian, C., Dennis, J., \& Rah, Y. (2002). Relative contributions of families and peers to children's social development. In P. K. Smith \& C. H. Hart (Eds.), Handbook of Childhood Social Development (pp. 156-177). Oxford: Blackwell.

Proulx, M.-F., \& Poulin, F. (2013). Stability and change in kindergarteners' Friendships: Examination of links with social functioning. Social Development, 22(1), 111-125. doi:10.1111/sode.12001

Rose-Krasnor, L., \& Denham, S. (2009). Social-emotional competence in early childhood. In K. H. Rubin, W. M. Bukowski, \& B. Laursen (Eds.), Handbook of peer interactions, relationships, and groups (pp. 162-179). New York: The Guilford Press.

Rubin, K. H., Bukowski, W., \& Parker, J. G. (2006). Peer interactions relationships, and groups. In N. Eisenberg, W. Damon, \& R. M. Lerner (Eds.), Handbook of child psychology: Social, emotional, and personality development (pp. 571-645). Hoboken, NJ: John Wiley \& Sons.

Rubin, K. H., Wojslawowicz, J. C., Rose-Krasnor, L., BoothLaForce, C., \& Burgess, K. B. (2006). The best friendships of shy/withdrawn children: Prevalence, stability, and relationship quality. Journal of Abnormal Child Psychology, 34(2), 139-153, doi:10.1007/s10802-005-9017-4

Salovey, P., \& Mayer, J. D. (1990). Emotional intelligence. Imagination, Cognition \& Personality, 9(3), 185-211.

Salvas, M.-C., Vitaro, F., Brendgen, M., Lacourse, E., Boivin, M., \& Tremblay, R. E. (2011). Interplay between friends' aggression and friendship quality in the development of child aggression during the early school years. Social Development, 20(4), 645-663. doi:10.1111/j.1467-9507.2010.00592.x

Sebanc, A. M., Kearns, K. T., Hernandez, M. D., \& Galvin, K. B. (2007). Predicting having a best friend in young children:
Individual characteristics and friendship features. The Journal of Genetic Psychology, 168(1), 81-96.

Shin, N., Kim, M., Goetz, S., \& Vaughn, B. E. (2014). Dyadic analyses of preschool-aged children's friendships: convergence and differences between friendship classifications from peer sociometric data and teacher's reports. Social Development, 23(1), 178-195. doi:10.1111/sode.12043

Spinrad, T. L., Eisenberg, N., Harris, E., Hanish, L., Fabes, R. A., Kupanoff, K., Ringwald, S., \& Holmes, J. (2004). The relation of children's everyday nonsocial peer play behavior to their emotionality, regulation, and social functioning. Developmental Psychology, 40(1), 67-80. doi:10.1037/00121649.40.1.67

Walden, T., Lemerise, E., \& Smith, M. C. (1999). Friendship and popularity in preschool classrooms. Early Education \& Development, 10(3), 351-371. doi:10.1207/s15566 935eed1003_7

Werner, N. E., Eaton, A. D., Lyle, K., Tseng, H., \& Holst, B. (2013). Maternal social coaching quality interrupts the development of relational aggression during early childhood. Social Development, 23(3), 470-486. doi:10.1111/sode.12048

\section{In Korean}

Kim, I. H., \& Kim, S. Y. (2017). The effects of children's emotion regulation ability and parental management strategies of peer relations and children's peer interaction during play. Journal of Life-span Studies, 7(1), 37-53.

Kim, J. S. (2011). An ehnographic study on a children's friend in a class of 3-year-old at kindergarten (Doctoral dissertation). Retrieved from http://www.riss.kr/link?id=T12648279

Kostelnik, M. J., Whiren, A. P., Soderman, A. K., \& Gregory, K. M. (2009). Guiding children's social development and learning (K. J. Park, S. Y. Kim, Y. H. Kwon, \& J. H. Kim, Trans.). Paju: Kyomonsa Press. (Original work published 2008).

Lee, J. Y., Kang, S. S., \& Lee, K. O. (2009). A study on the effects of young children's gender temperament and emotional intelligence and mothers' [eer management strategies on peer competence. Journal of Early Childhood Education, 29(5), 45-64.

Lee, B. N. (1997). Relationship between kindergartners' emotional intelligence and their parents' psychological life position (Unpublished doctoral dissertation). Chung-Ang University, Seoul, Korea.

Park, J. H. (2001). Children's peer competence in relation to maternal parenting goals, parenting behaviors, and management strategies of peer relations (Doctoral dissertation). Retrieved from http://www.riss.kr/link?id=T7912822

Park, M. H., \& Park, K. J. (2016). Stability in Friendship Patterns Among Kindergarteners: A Short-Term Longitudinal Study. 
Korean Journal of Child Studies, 37(1), 73-82. doi:10.5723/ kjcs.2016.37.1.73

Park, W. Y., \& An, R. R. (2006). A study of the Relationships between social Competence and Emotional Regulation Strategies used by 3,4 and 5-year-old children. Journal of Early Childhood Education, 26(4), 351-369.

Hwang, Y. M., \& Moon, H. J. (2010). The effects of young children and their mother's variables on peer acceptance of the children. Family and Environment Research, 48(6), 17-30.

\section{ORCID}

Mi Hyun Park

https://orcid.org/0000-0002-8703-0186

Kyung Ja Park

Received April 30, 2018

Revision received May 28, 2018

Accepted June 7, 2018 